\title{
La double complémentarité : ARN sens et antisens, peptides sens et antisens
}

Le schéma classique de la génétique moléculaire est que l'un des brins d'ADN est transcrit en ARN, lui-même traduit en protéine. Cependant, certaines cellules procaryotes synthétisent des ARN antisens, complémentaires d'une partie des ARN messagers ; s'hybridant à eux, ils perturbent leur traductibilité et peuvent ainsi réguler l'expression "phénotypique " du gène correspondant [1]. De tels phénomènes de régulation par des ARN antisens interviennent dans la limitation de la replication de plasmides, le contrôle de la transposition d'éléments mobiles, le cycle de phages et l'expression de certaines protéines d'E.coli [1]. Chez les eucaryotes, des ARN antisens naturels ont été décrits, mais ils sont rares et aucun argument formel n'indique qu'ils jouent un rôle physiologique [2]. En revanche, la possibilité d'inhiber la fonction d'un gène en introduisant ou en faisant synthétiser dans une cellule un ARN antisens, a fait l'objet de très nombreux travaux dont voici quelques exemples remarquables. Un plasmide contenant un ADN codant pour "l'anti-ARN " $c$-fos placé sous le contrôle d'un promoteur inductible peut, après introduction dans des fibroblastes et induction du promoteur, inhiber la prolifération des cellules en bloquant la synthèse de l'oncogène $c$ fos [3]. Selon le même principe, on a pu aussi inhiber, à l'aide d'un plasmide codant pour un " anti-ARN " actine, la synthèse endogène d'actine cytoplasmique [4]. En inhibant la fonction d'un gène, des ARN antisens peuvent mimer son inactivation complète, par exemple à la suite d'une délétion; on parle de " copie phénotypique " de la mutation, encore dénommée "phénocopie". Un exemple $m / s n^{\circ} 5$ vol. 3, mai 87 d'une telle phénocopie d'une mutation est donné par l'amibe Dictyostelium discoidum dont il existe des mutants dépourvus de discoïdine, une lectine de surface de l'amibe intervenant dans les contacts intracellulaires. Un phénotype identique à celui des mutants (c'est-à-dire des anomalies d'adhésion) peut être mimé par l'expression dans l'amibe d'ARN antisens complémentaire du messager de la discoïdine [5]. Chez la drosophile, on a même pu créer une telle phénocopie in vivo, c'est-à-dire un animal transgénique ayant intégré un brin d'ADN codant pour un ARN antisens complémentaire du messager Krüppel et ayant les mêmes anomalies de développement que les mutants authentiques pour ce gène contrôlant la différenciation des segments thoraciques et abdominaux antérieurs de l'insecte [6]. Les mécanismes de l'inhibition de l'expression d'un gène que provoque la présence d'ARN antisens sont au moins doubles. Dans le noyau, les transcrits antisens peuvent bloquer les réactions normales d'excision-épissage des transcrits sens. Dans le cytoplasme, les " anti-ARN " peuvent inhiber la traduction des messagers. L'efficacité de ces " anti-ARN " est d'ailleurs d'autant plus grande qu'ils hybrident avec la partie 5' des messagers, c'est-à-dire avec les motifs régulant l'initiation de la traduction. Les limitations pratiques de l'utilisation des ARN antisens pour tester le rôle physiologique d'un gène dont on pourrait à volonté bloquer l'expression (un oncogène, un gène homéotique, par exemple) restent cependant importantes et expliquent le petit nombre de résultats publiés jusqu'à présent. La principale de ces limitations est la nécessité d'une expression extrêmement active de l'ARN antisens pour obtenir un blocage presque complet de la fonction d'un gène : des excès de 50 fois de l'ARN antisens sur l'ARN sens peuvent être indispensables.

Une autre perspective ouverte par les ARN antisens est thérapeutique et passe par l'introduction dans la cellule d'oligonucléotides de synthèse complémentaires des ARN dont on veut inhiber l'expression. Si on parvient à " cibler" ces oligonucléotides vers une cellule particulière et à les faire pénétrer en quantité suffisante, ils pourront selon les cas être utilisés en thérapeutique antivirale, anti-parasitaire... ou anticancéreuse, via l'inhibition spécifique d'un oncogène activé. Dans tout ce qui précède, l'effet biologique de l'ARN antisens est dû au blocage de l'expression de l'ARN messager.

Plus récemment, une autre propriété possible et extrêmement intrigante des ARN antisens a été suggérée par Bost $e t$ al. : ils pourraient potentiellement coder pour des peptides qui seraient euxmêmes complémentaires des séquences peptidiques codées par le messager. Ainsi, un peptide antisens de l'ACTH (hormone corticotrope), désigné " HTCA ", a une affinité particulière pour l'ACTH [7]. Mieux même, un anticorps anti-HTCA possède une structure mimant celle de l'ACTH et se fixe aux récepteurs de l'hormone, stimulant la synthèse de glucocorticoïdes au niveau de cellules surrénaliennes de souris [8]. Ces anticorps peuvent d'ailleurs être utilisés en chromatographie d'immunoaffinité pour isoler le récepteur de I'ATCH, ce qui signifie que les structures du peptide HTCA et du récepteur de l'ACTH sont similaires. Ces résultats ont été 
confirmés en février 1987 par Shai et al. [9] qui ont utilisé un autre modèle, celui du peptide $S$, sens et antisens, de la ribonucléase pancréatique. La complémentarité possible de peptides codés par les deux brins complémentaires d'un gène est stupéfiante et reste de nature très mystérieuse, mais pourrait avoir une signification extrêmement importante dans la constitution au cours de l'évolution des couples ligandsrécepteurs. On connaissait jusqu'à présent le phénomène de redistribution des exons au cours de l'évolution, ou " exon shuffling " $\left(\mathrm{m} / \mathrm{s} n^{\circ} 1\right.$, vol. 2, p. 51), mécanisme de création de nouvelles spécificités à partir d'éléments préexistants. On pourrait imaginer que non seulement les exons peuvent s'associer variablement au cours de l'évolution, mais aussi s'intégrer dans l'un ou l'autre sens, codant ainsi pour des structures protéiques complémentaires: un récepteur et une hormone ou un neuromédiateur (par exemple l'ACTH et le récepteur de
l'ACTH comme suggéré dans la référence 8), ou encore une " adhésine " de la surface membranaire (par exemple les glycoprotéines IIIb-IIIa des plaquettes, voir $\mathrm{m} / \mathrm{s} n^{\circ} 6$, vol. 3) et les motifs peptidiques qu'elle reconnaît, comportant principalement les séquences maintenant classiques de ce type d'interaction, de formule RGD (S) (arginine, glycocolle, aspartique, (sérine)) (voir $\mathrm{m} / \mathrm{s}$ $n^{\circ} 6$, vol. 3). Le concept nouveau, véritablement révolutionnaire suggéré par les résultats que nous rapportons, est que le " code de la communication cellulaire " dont parle Claude Kordon dans l'éditorial de $\mathrm{m} / \mathrm{s} n^{\circ} 3$, vol. 3, page 126 est, au départ au moins, un reflet de la complémentarité des acides nucléiques. Un gène ancestral pourrait être à l'origine d'une famille de récepteurs (ou de ligands protéiques) par l'un de ses brins... et d'une famille de ligands protéiques (ou de récepteurs) par l'autre!

A.K.
1. Green PJ, Pines $\mathrm{O}$, Inouye $\mathrm{M}$. The role of antisense RNA in gene regulation. Ann Rev Biochem 1986 ; 55 : 569-97.

2. Kioussis D, Grosveld F. Naturally occuring complementary transcripts : do they function as anti-sense RNA ? Trends in Genelics 1986 ; 2 : 304 .

3. Holt JT, Gopal TV. Moulton AD, Nienhuis AW. Inducible production of $c$-f os antisense RNA inhibits 3T3 cell proliferation. Proc Nall Acad Sci USA 1986 ; 83 : 4794-8.

4. Izant JG, Weintraub $H$. Constitutive and conditional suppression of exogenous and endogenous genes by anti-sense RNA. Science 1985 ; 229 : $345-52$.

5. Crowley TE, Nellen W, Gomer RH, Firtel RA. Phenocopy of discoidin I-minus mutants by antisense transformation in dictyostelium. Cell $1985 ; 43$ : 633-41.

6. Rosenberg UB, Preiss A, Seifert E, Jäckle $\mathrm{H}$, Knippel LE. Production of phenocopies by Krüppel antisense RNA injection into drosophila embryos. Nalure 1985 ; 313 : 703-6.

7. Blalock JE, Bost KL. Binding of peptides that are specified by complementary RNAs. Biochem J 1986 ; 234 : 679-83.

8. Bost KL, Smith EM, Blalock JE. Similarity between the corticotropin (ACTH) receptor and a peptide encoded by an RNA that is complementary to ACTH mRNA. Proc Nall Acad Sci USA $1985 ; 82$ : 1372-5.

9. Shai Y, Flashner M, Chaiken IM. Antisense peptide recognition of sense peptides direct quantitative characterization with the ribonuclease S-peptide system using analytical high performance affinity chromatography. Biochemistry $1987 ; 27: 669-75$.

\section{口ם BRÈVES}

$\square$ Utiliser des anticorps comme des enzymes est possible ! Le principe est de développer des anticorps reconnaissant spécifiquement des " états de transition" réactifs des molécules à modifier [1]. Par exemple, si une réaction s'écrit : $A \leftrightarrows A / B \Rightarrow B, A$ et $B$ étant les produits extrêmes de la réaction et $\mathrm{A} / \mathrm{B}$ un état de transition réactif et instable, un anticorps spécifiquement dirigé contre l'espèce A/B la stabilisera et augmentera la vitesse de la réaction. Des anticorps monoclonaux dirigés contre de telles espèces réactives ont en effet été préparés par deux équipes [2, 3] ; ils augmentent de 1000 à 15000 fois la vitesse de la réaction spontanée, actifs que de véritables enzymes. L'activité catalytique de ces " ACzymes " doit cependant pouvoir être améliorée. La taille du répertoire des anticorps est telle que ces résultats ouvrent la perspective de créer à volonté des catalyseurs biologiques de réactions auxquelles ne correspond aucune enzyme. On pourrait ainsi envisager de " fabriquer " des "AC-zymes " spécifiques de toutes les séquences peptidiques désirées, équivalentes, pour les protéines, des enzymes de restriction pour l'ADN.

[1. Marx JL. Science 1986 ; 234 : 1497-8]

[2. Tramontano A, et al. Science 1986 ; 234 : 1566-70]

[3. Pollack SJ, et al. Science 1986 ; 234: 1570-3]
L'interféron $\beta_{2}$, une molécule à faible activité antivirale mais douée d'une puissante activité antiproliférative, est la même molécule que le BSF $_{2}$ (ou $B C D F$, " $B$ cell différentiation factor "), lymphokine sécrétée par les lymphocytes $T$ et intervenant dans la différenciation des lymphocytes B. Cette dualité d'action ne doit d'ailleurs pas surprendre puisque l'on savait déjà que l'interféron $\gamma$, également sécrété par les lymphocytes $T$, pouvait lui aussi être considéré comme une lymphokine active sur les lymphocytes B murins et humains.

[Revel M, Zilberstein A. Nature $1987 ; 325$ : 581-2] 